\title{
Temperature Reduction of Concrete Pavement Using Glass Bead Materials
}

\author{
Erhan Burak Pancar'), and Muhammet Vefa Akpınar ${ }^{2), *}$
}

(Received August 22, 2015, Accepted February 5, 2016, Published online February 29, 2016)

\begin{abstract}
In this study, different proportions of glass beads used for road marking were added into the concrete samples to reduce the temperature gradient through the concrete pavement thickness. It is well known that decreasing the temperature gradient reduces the risk of thermal cracking and increases the service life of concrete pavement. The extent of alkali-silica reaction (ASR) produced with partial replacement of fine aggregate by glass bead was investigated and compressive strength of concrete samples with different proportion of glass bead in their mix designs were measured in this study. Ideal results were obtained with less than $0.850 \mathrm{~mm}$ diameter size glass beads were used (19\% by total weight of aggregate) for C30/37 class concrete. Top and bottom surface temperatures of two different $\mathrm{C} 30 / 37$ strength class concrete slabs with and without glass beads were measured. It was identified that, using glass bead in concrete mix design, reduces the temperature differences between top and bottom surfaces of concrete pavement. The study presented herein provides important results on the necessity of regulating concrete road mix design specifications according to regions and climates to reduce the temperature gradient values which are very important in concrete road design.
\end{abstract}

Keywords: concrete road, glass bead, temperature gradient, thermal conductivity.

\section{Introduction}

Portland cement concrete (PCC) pavements are usually exposed to repeated dynamic loads produced by heavy truck traffic, as well as deformations caused by various climatic conditions. Temperature is one of the most important environmental factors for designing and predicting performance of PCC pavements. Temperature gradients throughout the slab thickness play a key role in calculating thermal stresses in PCC pavements, known as curling (Huang 2004). It is necessary to increase the performance of PCC pavement by decreasing the curling stresses resulting from the fluctuation of temperature gradients.

Kim and Chun (2015) monitored the temperature gradients in the test slab during Jan 12-Feb 2 of 2015 using instrumented thermocouples at different depths. The maximum positive temperature differential for the internally cured concrete (ICC) slab was about $7.8{ }^{\circ} \mathrm{C}$ at $3-4$ p.m., while the maximum negative temperature differential was $-6.7^{\circ} \mathrm{C}$ at 11-12 p.m. However, for the standard mix slab, the maximum temperature gradients were 5.0 and $-4.4{ }^{\circ} \mathrm{C}$ at the

\footnotetext{
${ }^{1)}$ Department of Architecture, Ondokuz Mayıs

University, Samsun, Turkey.

${ }^{2)}$ Department of Civil Engineering, Karadeniz Technical University, Trabzon, Turkey.

*Corresponding Author; E-mail: mvakpinar@ktu.edu.tr Copyright $($ The Author(s) 2016. This article is published with open access at Springerlink.com
}

same time. This indicates that the temperature differentials of the ICC slab are higher than that of the standard mix slab. They mentioned that the low thermal conductivity of the ICC slab prevents the ICC slab from the fast temperature change inside the concrete slab that may lead to the higher temperature differentials in ICC slabs.

Ham and Oh (2013) studied the portland cement concrete exposed to high temperatures during mixing, transporting, casting, finishing, and curing can develop undesirable characteristics. They evaluated the hardened properties of the concrete exposed to hot weather in fresh state. Core samples were obtained from the field locations and were analyzed by based on the standard resonance frequency analysis and the boil test results, they showed that there does not appear to be systematic evidence of frequent cracking problems related to high temperature placement.

Thermal conductivity and heat capacity are used to estimate the temperature gradient of concrete pavement (Heydinger 2003). Decreasing the thermal conductivity and heat capacity of concrete also decrease the temperature gradient of concrete road. This can be made by replacing some proportion of aggregates with another material having a lower thermal conductivity and heat capacity in concrete mix design. It must not be neglected to remain mechanical properties of concrete while doing this regulation and the added material must not exhibit an increased risk of alkalisilica reaction (ASR). ASR occurs in concrete when alkalis from cement reacts with free silica presented in certain aggregates to form alkali-silica gels (New York State Energy Research and Development Authority 1997; Graham 1996). 
In this study, four different type of concrete mixtures with different proportions (0-9-19-31\%) of glass bead, which was used as a fine aggregate, were prepared. ASR of these glass bead proportions were measured. Compressive strength of ternary concrete mixtures (0-9-19-31\% glass bead by total weight of aggregate) were performed at 28 days in order to choose the ideal concrete mix design to obtain smaller temperature difference between top and bottom surface of concrete slab on site. Two different type of concrete slabs with $1 \mathrm{~m} \times 1 \mathrm{~m} \times 25 \mathrm{~cm}$ dimensions were placed on base course layer. These slabs had different proportions of glass beads in their mix designs. The top and bottom surface temperatures of these two slabs and air temperature were measured between 08:00 and 16:00 $\mathrm{h}$ in summer on Black Sea Region of Turkey. It was observed how using glass in concrete mix design change the top and bottom surface temperatures of concrete slabs.

\section{Thermal Effect in PCC Pavements}

PCC pavements are affected by temperature differences. Figure 1 illustrates the PCC pavement deformation caused by environmental effects. Figures $1 \mathrm{a}$ and $1 \mathrm{~b}$ show the pavement deformation caused by temperature variation throughout the slab thickness during the day and night, respectively.

The temperature at the top surface of the slab is higher than that of the bottom during the day. The top tends to expand while the bottom tends to contract (Fig. 1a). But the weight of the slab restrains them, and tensile stresses are induced at the bottom of the slab (Huang 2004) as illustrated in Fig. 2a. Bottom-up transverse cracking can develop when heavy traffic loads are applied near the center of the slab simultaneously.

The temperature at the top surface of the slab is lower than that of the bottom at night and the top tends to contract (Fig. 1b). The self-weight of the slab constrains the top surface from contraction, which produces tensile stresses at the top of the slab (Huang 2004). This is illustrated in Fig. 2b. Top-down transverse cracking can develop on the

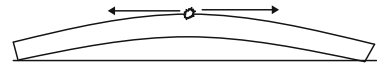

(a)

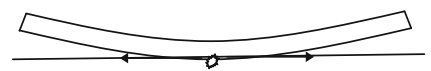

(b)
Fig. 1 Pavement deformation and tensile stress during day and night (arrows denote tensile stress). a Deformation during the day. $\mathbf{b}$ Deformation during the night.

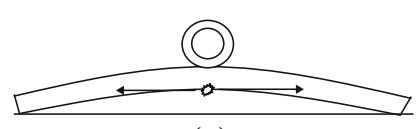

(a)

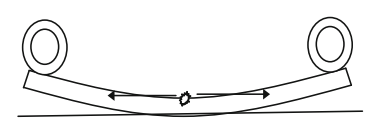

(b)
Fig. 2 Tensile stresses according to loading during day and night (arrows denote tensile stress). a Loading near the center of the slab. b Loading at the edge of the slab. slab surface when heavy traffic loads are applied at the edge of the slab at the same time.

Richardson and Armaghani (1990) and Shoukry and Fahmy (2002), have determined that differential temperature was $10{ }^{\circ} \mathrm{C}$ through $225 \mathrm{~mm}$ concrete slab. Byrum and Hansen (1994), used the differential temperature value as between 0.087 and $0.109{ }^{\circ} \mathrm{C} / \mathrm{mm}$ during the day time and between 0.044 and $0.065{ }^{\circ} \mathrm{C} / \mathrm{mm}$ during the night time in their study. Kuo (1998) recommended to use loading at the center of the slab during the day time and loading at the edge of the slab at night time in analyzing of concrete pavement. Negative temperature gradient (night time) is not taking into account especially at concrete road design in Germany. This is because, negative gradient is less than positive gradient (day time) (VENCON 2.0 2004).

Due to the variable characteristics of curling stresses resulting from the daily and seasonal fluctuation of temperature gradients, an accurate measurement of temperature gradients at various climatic conditions is necessary to correctly predict the performance of PCC pavement.

\section{Thermal Conductivity (TC) and Heat Capacity (HC)}

Thermal conductivity and heat capacity are pertinent to the temperature profiles throughout the slab thickness and thermal cracking of PCC pavements. Thermal conductivity represents a uniform heat flow through a unit thickness of material between two faces of unit area that are subjected to a unit temperature difference (Mindess et al. 2003). The thermal conductivity of water is less than that of cement paste, thus a lower w/c ratio of cement paste has a higher thermal conductivity. The thermal conductivity of water and air are remarkably lower than that of solid materials, so that the degree of saturation and density of specimen have a great impact on the thermal conductivity values of concrete (Mindess et al. 2003).

Kim et al. (2003) studied the seven parameters that mostly affect thermal conductivity and determined that the aggregate volume fraction and moisture condition of both cement paste and concrete specimens are the most influential factors on thermal conductivity value Thermal conductivity of quartzite, sandstone, limestone, basalt, water and air are 4.3; $3.9 ; 3.1 ; 1.4 ; 0.5$ and $0.03 \mathrm{~W} / \mathrm{mK}$ respectively.

Heat capacity is defined as the ability of a given volume of a substance to store internal energy, while undergoing a given temperature change (Btu. per lb. per $1^{\circ} \mathrm{F}$ ) (Rohsenow et al. 1998). Heat capacity is little affected by the type of aggregate, since heat capacity is not sensitive to mineralogical characteristics (Mindess et al. 2003).

Michal et al. (2015) studied the possibility of adding lightweight building aggregates to increase the thermal stability of constructions and road objects. The stability was achieved through saturating the porous granules of aggregate with a phase-change material (PCM) that allows the accumulation of solar heat. Simulation tests conducted under real conditions on two asphalt surfaces $(0.32 \times 0.22 \times 0.15 \mathrm{~m})$, 
one of which contained the PCM while the other did not, have shown that even a small addition of ceresin $(3 \%$ mass relative to the weight of the ground) causes a reduction in surface temperature of about $5 \mathrm{~K}$ within the tested temperature range of $318.15-338.15 \mathrm{~K}$.

\section{Glass in Concrete}

It is known that, water absorption capacity of glass is almost zero and when it is used as an aggregate in concrete, it decreases the water absorption and drying shrinkage values which is a desired property for concrete (Lam et al. 2007).

Glass has a higher value of $\mathrm{SiO}_{2}$ and it is observed whether alkali-silica reaction (ASR) expansion would be seen or not in concrete with glass in its mix design when there is enough moisture by Lam et al. (2007). It was observed that, if the proportion of the glass is lower than $25 \%$ weight of the aggregate in concrete, ASR expansions are in negligible level.

Byars and Zhu determined that, the reactivity of glass particles generally increases with particle size from around 1-2 mm. Glass particles below this size appear to reduce the propensity for ASR in larger glass particles. Ready-mixed concrete made with glass pozzolan and/or glass sand shows increasing in strength development to 1 year, indicating a pozzolanic contribution from the fine glass particles (Byars et al. 2004).

In this study, glass beads shown on Fig. 3 which are used for road marking and has a density of $1.6 \mathrm{~g} / \mathrm{cm}^{3}$ were used as a fine aggregate to reduce the temperature gradient in concrete road. Thermal conductivity of glass beads used in this study was about $0.0014 \mathrm{~W} / \mathrm{mK}$. Heat capacity of glass beads and concrete were $1200,880 \mathrm{~J} / \mathrm{kg}{ }^{\circ} \mathrm{C}$, respectively. The chemical properties of the fine aggregate, coarse aggregate and glass bead which were used in this study to determine the ideal concrete mix design to reduce the top and bottom surface temperature difference of concrete slab on the site are in Table 1. The properties of portland cement (PC 42.5) used in this study are shown in Table 2. Sphericity of glass beads was more than $70 \%$. Sieve analysis of fine aggregate and glass beads used in concrete mix design are

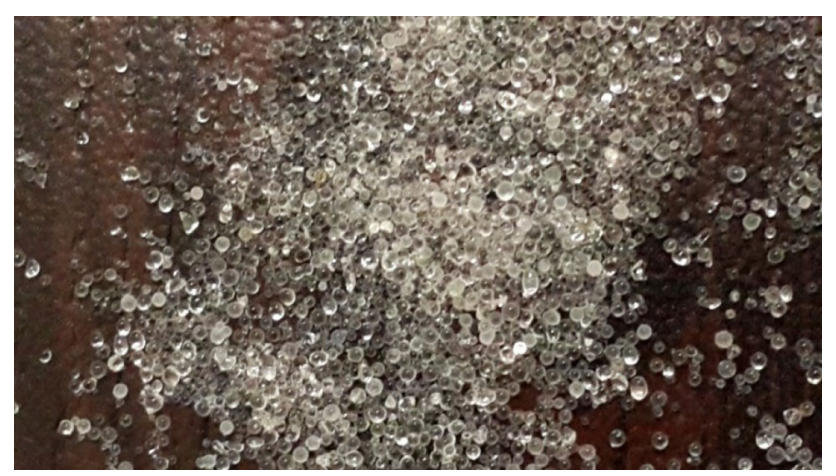

Fig. 3 Glass beads used as a fine aggregate to reduce the temperature gradient in concrete sample. shown in Tables 3 and 4 respectively. The density of the sand used as a fine aggregate was $2.63 \mathrm{~g} / \mathrm{cm}^{3}$.

\section{ASR and Compressive Strength of Concrete with Glass Beads}

The potential ASR expansion of the prepared mortar bars $(25 \times 25 \times 285 \mathrm{~mm})$ with a water to cement ratio of 0.47 was assessed in accordance with ASTM C1260 $\left(80^{\circ} \mathrm{C}, 1 \mathrm{~N}\right.$ $\mathrm{NaOH}$ ) (ASTM C1260 2001). Four series of mortar bars were prepared in total. In these series, different proportion (0-9-19-31\%) of glass beads were prepared. The test period was 28 days. The result of mortar bars test are shown in Fig. 4 which indicate that the ASR expansion was able to meet the requirements prescribed in ASTM C1260 $(<0.1 \%$ within 14 days) for every mortar bars used in the test. Mix proportions of mortar bars are in Table 5 .

Standard $15 \mathrm{~cm} \times 15 \mathrm{~cm} \times 15 \mathrm{~cm}$ cube C30/37 strength class concrete specimens were prepared for the testing program. Glass beads replaced with 9-19-31\% weight of the total aggregate and compressive strength of ternary concrete mixtures were performed at the end of 28 days in order to choose the maximum glass proportion which provides necessary compressive strength in the evaluated type of concrete. The mix designs of concrete samples are in Table 6 and the compressive strengths of these samples according to proportion of glass beads in their mixtures are in Table 7.

The minimum compressive strength should be at least $37 \mathrm{MPa}$ at the end of 28 days and $31 \%$ proportion of glass beads did not provide this value. $19 \%$ glass bead by weight of the total aggregate provided the minimum compressive strength of the $\mathrm{C} 30 / 37$ strength class concrete. $19 \%$ proportion of glass beads used in this study was in acceptable limit for ASR. The density of concrete according to glass bead proportion in its mix design is in Table 8 . The density of concrete decreases when the proportion of glass increases.

\section{Temperature Measurement in PCC Pavement}

In this part of the study, two different type of concrete, C30/37 strength class without any glass bead and with glass bead (19\% by weight of total aggregate) were placed on a base course layer ( $25 \mathrm{~cm}$ thick crushed limestone). $19 \%$ proportion of glass bead was in acceptable limit for compressive strength test and ASR in this study. The dimensions of these two slabs were $1 \mathrm{~m} \times 1 \mathrm{~m}$ and $25 \mathrm{~cm}$ thick. In order to monitor the daily variations of temperature profiles, temperature sensors were installed in the middle of the top and bottom of the slabs. Temperatures were measured between 08:00 and 16:00 h. Because, positive gradient is more important than negative gradient in concrete road design. The test was performed on 03 August 2014 in north side of Turkey. Figure 5 shows the temperature profile of top 
Table 1 Chemical properties of fine aggregate, coarse aggregate and glass bead.

\begin{tabular}{c|c|c|c}
\hline Oxide & Fine aggregate & Coarse aggregate & Glass bead \\
\hline \hline $\mathrm{SiO}_{2}(\%)$ & 2.59 & 38.76 & 69.80 \\
\hline $\mathrm{Al}_{2} \mathrm{O}_{3}(\%)$ & 1.09 & 17.65 & 1.45 \\
\hline $\mathrm{CaO}(\%)$ & 95.09 & 13.00 & 9.52 \\
\hline $\mathrm{MgO}(\%)$ & - & 6.33 & 4.20 \\
\hline $\mathrm{Fe}_{2} \mathrm{O}_{3}(\%)$ & 0.92 & 13.56 & 0.15 \\
\hline $\mathrm{K}_{2} \mathrm{O}(\%)$ & 0.17 & 2.12 & 0.72 \\
\hline $\mathrm{Na}_{2} \mathrm{O}(\%)$ & - & 6.52 & 13.85 \\
\hline
\end{tabular}

Table 2 Properties of cement.

\begin{tabular}{c|c}
\hline Properties & Cement (PC 42.5) \\
\hline $\mathrm{SiO}_{2}(\%)$ & 20.81 \\
\hline $\mathrm{Al}_{2} \mathrm{O}_{3}(\%)$ & 5.41 \\
\hline $\mathrm{CaO}(\%)$ & 62.3 \\
\hline $\mathrm{MgO}(\%)$ & 0.97 \\
\hline $\mathrm{Fe}_{2} \mathrm{O}_{3}(\%)$ & 3.72 \\
\hline $\mathrm{Na}_{2} \mathrm{O}+\mathrm{K}_{2} \mathrm{O}(\%)$ & 0.43 \\
\hline $\mathrm{SO}_{3}(\%)$ & 3.07 \\
\hline Density $\left(\mathrm{g} / \mathrm{cm}^{3}\right)$ & 3.17 \\
\hline
\end{tabular}

Table 3 Sieve analysis of fine aggregate.

\begin{tabular}{c|c}
\hline Sieve size in $(\mathrm{mm})$ & Percentage passing by weight (\%) \\
\hline \hline 4 & 100 \\
\hline 2 & 81.4 \\
\hline 1 & 55.2 \\
\hline 0.5 & 38.8 \\
\hline 0.25 & 27.2 \\
\hline 0.063 & 12.4 \\
\hline
\end{tabular}

Table 4 Sieve analysis of glass bead (ISO 565 R40/3 sieves were used).

\begin{tabular}{c|c}
\hline Sieve size in $(\mathrm{mm})$ & Percentage passing by weight (\%) \\
\hline 0.850 & 99.8 \\
\hline 0.710 & 95.2 \\
\hline 0.600 & 79.0 \\
\hline 0.425 & 47.3 \\
\hline 0.300 & 20.0 \\
\hline 0.180 & 3.7 \\
\hline
\end{tabular}

surface of the standard C30/37 strength class concrete slab and the air.

Figure 5 shows that there is a temperature difference between the top surface of the slab and the air. This difference is $2.6{ }^{\circ} \mathrm{C}$ at $08: 00$ and $17.5{ }^{\circ} \mathrm{C}$ at $14: 00$.
Figure 6 shows the temperature of top and bottom surface of standard C30/37 concrete slab between 08:00 and 16:00. The highest top surface temperature was at 14:00 with a value of $49.7^{\circ} \mathrm{C}$. The biggest temperature difference on top of the slab was $23.3{ }^{\circ} \mathrm{C}$ during the testing time. The highest 


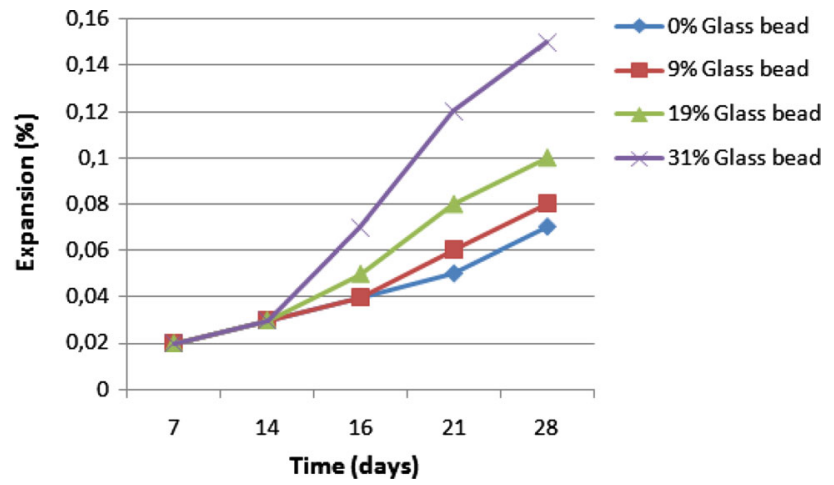

Fig. 4 Results of ASR expansion of the mortar bars with different proportions of glass bead.

bottom surface temperature was at 16:00 with a value of $36.4{ }^{\circ} \mathrm{C}$. The biggest temperature difference on bottom of the slab was $11.8^{\circ} \mathrm{C}$ during the testing time. The biggest temperature difference between top and bottom of the slab was at $14: 00$ with a value of $14{ }^{\circ} \mathrm{C}$. It is interesting to know that the top and bottom temperatures were same at morning and evening indicating $\Delta \mathrm{T}=0$.

Base on the data given on Fig. 6 two regression model can be developed with high correlation coefficient values:

Top Surface Temperature (C)

$$
\begin{aligned}
& =-0.785 \times \text { Time }^{2}+10.419 \times \text { Time }+12.878 \\
& \mathrm{R}^{2}=0.9188
\end{aligned}
$$

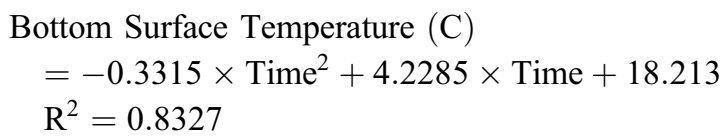

Both polynomial shaped models indicate that the temperatures varied in the sinusoidal form for the time durations studied. Similar trends were observed with concrete samples containing glass beads.

Table 5 Mix proportion of mortar bars.

\begin{tabular}{c|c|c|c|c}
\hline Glass bead proportion (\%) & Cement $(\mathrm{g})$ & Water $(\mathrm{g})$ & Fine aggregate $(\mathrm{g})$ & Glass bead $(\mathrm{g})$ \\
\hline \hline 0 & 440 & 207 & 990 & - \\
\hline 9 & 440 & 207 & 901 & 89 \\
\hline 19 & 440 & 207 & 802 & 188 \\
\hline 31 & 440 & 207 & 683 & 307 \\
\hline
\end{tabular}

\begin{tabular}{|c|c|c|c|c|c|c|c|}
\hline $\begin{array}{c}\text { Strength class } \\
\text { C } 30 / 37\end{array}$ & $\begin{array}{c}\text { Cement PC } 42.5 \\
(\mathrm{~kg})\end{array}$ & Water (kg) & Glass bead $(\mathrm{kg})$ & $\begin{array}{c}\text { 0/4 Fine } \\
\text { aggregate }(\mathrm{kg})\end{array}$ & $\begin{array}{c}7 / 15 \text { Coarse } \\
\text { aggregate }(\mathrm{kg})\end{array}$ & $\begin{array}{c}15 / 25 \text { Coarse } \\
\text { aggregate }(\mathrm{kg})\end{array}$ & Admixture (g) \\
\hline $0 \%$ Glass bead & 1.50 & 0.87 & 0 & 4.874 & 2.343 & 2.164 & 18 \\
\hline $9 \%$ Glass bead & 1.50 & 0.87 & 0.798 & 3.562 & 2.343 & 2.164 & 18 \\
\hline $19 \%$ Glass bead & 1.50 & 0.87 & 1.597 & 2.25 & 2.343 & 2.164 & 18 \\
\hline $31 \%$ Glass bead & 1.50 & 0.87 & 2.395 & 0.937 & 2.343 & 2.164 & 18 \\
\hline
\end{tabular}

Table 6 C30/37 strength class concrete mix design.

Table 7 Compressive strength of concrete samples at 28 days.

\begin{tabular}{c|c|c}
\hline Strength class & $\begin{array}{c}\text { Glass bead proportion (\% weight } \\
\text { of aggregate) }\end{array}$ & Compressive strength (MPa) \\
\hline \hline $\mathrm{C} 30 / 37$ & 0 & 48.06 \\
\hline $\mathrm{C} 30 / 37$ & 9 & 32.48 \\
\hline $\mathrm{C} 30 / 37$ & 19 & 39.65 \\
\hline $\mathrm{C} 30 / 37$ & 31 & 35.57 \\
\hline
\end{tabular}

Table 8 Density of C30/37 strength class concrete according to glass bead proportion.

\begin{tabular}{c|c}
\hline Glass bead (\%) in mix design & Unit weight $\left(\mathrm{kg} / \mathrm{m}^{3}\right)$ \\
\hline 0 & 2630 \\
\hline 9 & 2490 \\
\hline 19 & 2340 \\
\hline 31 & 2200 \\
\hline
\end{tabular}




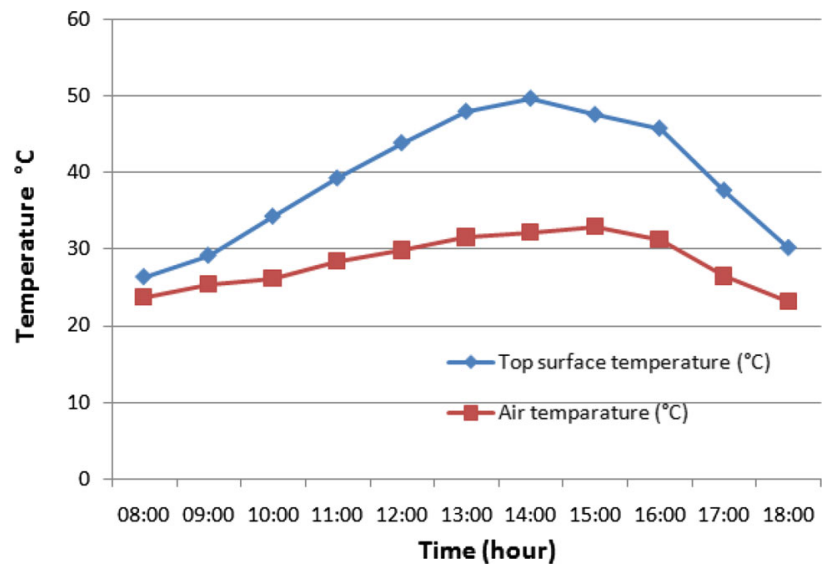

Fig. 5 Air temperature and top surface temperature of concrete on 03 August 2014 in Samsun, Turkey.

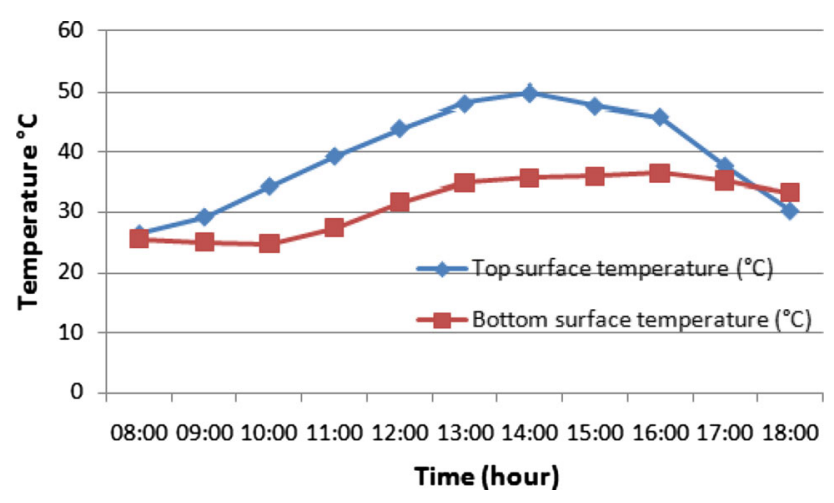

Fig. 6 Top and bottom surface temperature of C30/37 strength class concrete ( $0 \%$ glass bead).

\subsection{Modelling Temperature Versus Time}

Figure 6 shows the temperature of top surface of concrete slab (19\% glass beads in its mixture) between 08:00 and 16:00. The highest top surface temperature was at 14:00 with a value of $37.2^{\circ} \mathrm{C}$. The biggest temperature difference on top of the slab was $15.8{ }^{\circ} \mathrm{C}$ during the testing time. The highest bottom surface temperature was at 16:00 with a value of $34.9^{\circ} \mathrm{C}$. The biggest temperature difference on bottom of the slab was $9.8^{\circ} \mathrm{C}$ during the testing time. The biggest temperature difference between top and bottom of the slab was at $14: 00$ with a value of $3.5^{\circ} \mathrm{C}$.

Figure 7 shows the temperature differences of top surface layers of standard C30/37 strength class concrete slab and the concrete slab which has $19 \%$ glass beads in its mix design. The biggest temperature difference was at 14:00 and the top surface temperature of standard concrete slab was $12.5^{\circ} \mathrm{C}$ more than the other slab's top surface temperature at that time.

Figure 8 shows the temperature differences of bottom surface layers of standard C30/37 strength class concrete slab and the concrete slab which has $19 \%$ glass beads in its mix design. The temperature differences were between 0.2 and $3.5^{\circ} \mathrm{C}$. When Figs. 7 and 8 are compared each other, temperature differences of top surface layers are higher than bottom surface layers for both concrete slabs.

Figure 9 shows the bottom surface temperature of December month for $\mathrm{C} 30 / 37$ strength class concretes with 0

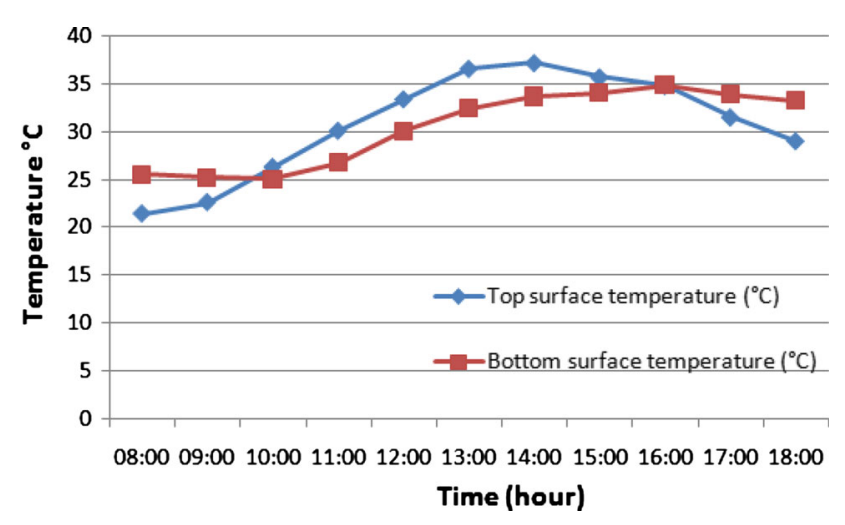

Fig. 7 Top and bottom surface temperature of C30/37 strength class concrete (19\% glass bead).

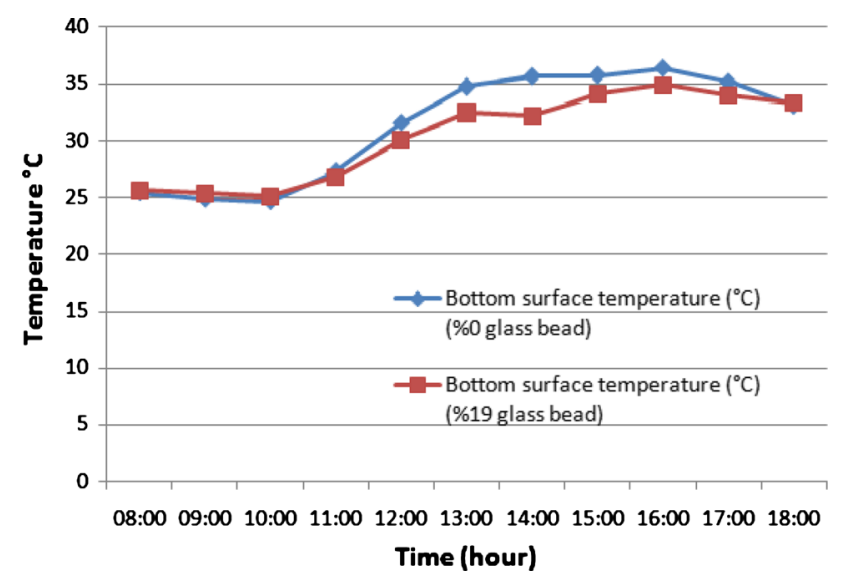

Fig. 8 Bottom surface temperature of C30/37 strength class concretes with 0 and $19 \%$ glass bead in their mix designs.

and $19 \%$ glass bead in their mix designs. In contrast to the hot season temperature graphs, the graph exponentially decreases to a certain temperature point before midnight and becomes steadily for the measured time duration between midnight and morning. The relationship between time and temperature variation for this study can be given as follows.

$$
\text { Air Temperature }\left({ }^{\circ} \mathrm{C}\right)=9.8083 \mathrm{e}^{-0.039 \text { Time }} \quad \mathrm{R}^{2}=0.8185
$$

Top Surface Temperature $\left({ }^{\circ} \mathrm{C}\right)=16.938 \mathrm{e}^{-0.04 T i m e}$ $\mathrm{R}^{2}=0.9096$

$$
\begin{aligned}
& \text { Bottom Temperature }\left({ }^{\circ} \mathrm{C}\right)=23.377 \mathrm{e}^{-0.019 \text { Time }} \\
& \mathrm{R}^{2}=0.6855
\end{aligned}
$$

The correlation coefficient value for air-time model was lower than the bottom and top surface models due to the fact that air temperature varies a lot and the materials can distribute the temperature more homogenous through the surface. Adding glass beads did not change the top surface temperature very much for ow temperatures. The differences between air, top and bottom were almost identical and was about $5-6{ }^{\circ} \mathrm{C}$ increment for the same time durations.

The albedo is an important in climatology and computing reflectivity of material surfaces especially in city centers $(\mathrm{Li}$ 


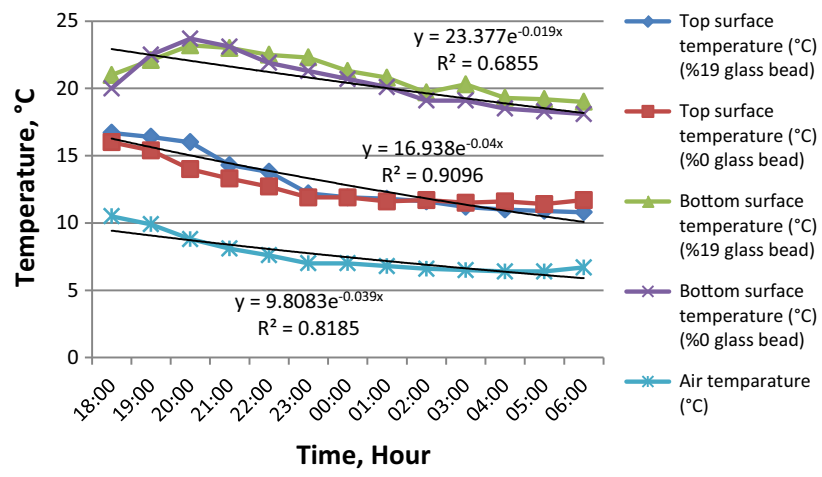

Fig. 9 Bottom surface temperature of December month for C30/37 strength class concretes with 0 and $19 \%$ glass bead in their mix designs.

et al. 2012, 2013; Kanok and Farhad 2007). The reflection coefficient or albedo was not measured by a device in this study. However based on visual observation of the radiation reflection an albedo value of 0.5 was estimated. 50 percentage of the light focused on the concrete samples were reflected. The ratio of reflected radiation from the concrete sample surface to the light source upon it was $50 \%$. At least $50 \%$ was not reflected. Albedo can be expressed as a percentage and is measured on a scale from zero for no reflection such as asphalt surface $(0.05-0.15)$ to 1 for perfect reflection of a white surface. Albedo value can vary between 0.4 and 0.8 for white portland cement concretes. The estimated 0.5 value may increase over the years once the concrete pavement opens to traffic and tires start to wear the surface where later the glass beeds may dominate the surface. The glass beads are used for good night vision on roads especially at nights. Instead of scattering light, glass beads turn the light around and send it back in the direction of the source. The glass bead's refractive index (RI) is an important physical parameter. The higher the RI of the bead and the fewer impurities in the glass material, the more light is retroreflected. Beads used in this study had RI of 1.5.

Techniques of creating a cool pavement can be classified into two groups based on their mechanism mainly increasing surface reflectance and increasing permeability $(\mathrm{Li}$ et al. 2012, 2013). Since research in the area of cool pavements is in an early stage, more techniques will continue to be developed. In this study, different proportions of glass beads, which are used for road marking, were added into the concrete samples to reduce the temperature gradient values representing the temperature changes through the concrete pavement thickness.

\section{Conclusion}

Temperature gradients are very important parameters in concrete road design. If this value is high, it is probable to see cracks on concrete road. Because of that, it is not enough to obtain necessary strength for a given concrete strength class. It must be studied to obtain concrete with lower thermal conductivity to decrease the temperature gradients on concrete road during a day. The first concern of this study was to decrease the temperature gradient while remaining the concrete strength at the necessary limit. Glass beads which have lower thermal conductivity were used for this purpose. Using glass beads in the mixture of concrete, also decreased the density of concrete. Besides reducing the thermal conductivity of concrete, the glass beads alleviate the dead load of the concrete pavement and thus reducing the vertical stresses over the base course layer. Glass bead, which is $19 \%$ by weight of the total aggregate in concrete, was suitable to get enough compressive strength for C30/37 strength class concrete and ASR expansion was able to meet the requirements for this proportion of glass bead.

After measuring two different mix design $(0-19 \%$ glass bead by total weight of aggregate) concrete slabs' surface temperatures during the day in summer, it was obtained that, concrete surface temperature was higher than air temperature between 08:00 and 16:00 h. Top surface temperature differences were higher than bottom ones. Using glass beads reduced top surface temperature of concrete. The biggest temperature difference between top and bottom surface of standard C30/37 strength class concrete was $14{ }^{\circ} \mathrm{C}$ at $14: 00$ while the difference was $3.5^{\circ} \mathrm{C}$ for the concrete with $19 \%$ glass beads in its mixture. Temperature differences between top and bottom surface of the concrete slab decrease by using glass beads in concrete mix design. Concrete road mix design specifications need to be regulated according to regions and climates to reduce the temperature gradient values and waste glass, which is needed to be used in sustainability, can also be used in concrete pavement mixture design in this purpose.

\section{Open Access}

This article is distributed under the terms of the Creative Commons Attribution 4.0 International License (http://creativecommons.org/licenses/by/4.0/), which permits unrestricted use, distribution, and reproduction in any medium, provided you give appropriate credit to the original author(s) and the source, provide a link to the Creative Commons license, and indicate if changes were made.

\section{References}

ASTM C1260. (2001). Standard test method for potential alkali reactivity of aggregates (mortar-bar method). West Conshohocken, PA: Annual Books of ASTM Standards.

Byars, E. A., Morales-Hernandez, B., \& Zhu, H. Y. (2004). Waste glass as concrete aggregate and pozzolan. Concrete, London, 38(1), 41-44.

Byrum, C. R., \& Hansen, W. (1994). Influence function approach to analysis of jointed portland cement concrete pavement. Transportation Research Record, 1449, $148-158$.

Graham, W. (1996). Alkali-aggregate reaction in concrete roads and bridge. London, UK: Thomas Telford. 
Ham, S., \& Oh, T. (2013). Effect of mixing and placing in hot weather on hardened concrete properties. International Journal of Concrete Structures and Materials, 7(2), 165-174.

Heydinger, A. G. (2003). Monitoring seasonal instrumentation and modeling climatic effect on pavements at the Ohio/ SHRP Test Road, FHWA/HO-2003/018.

Huang, Y. H. (2004). Pavement analysis and design (2nd ed.). Upper Saddle River, NJ: Prentice Hall Inc.

Kanok, B., Farhad, R. (2007). Mix design and benefit evaluation of high solar reflectance concrete for pavements. 86th Annual Meeting of the Transportation Research Board, Washington, D.C.

Kim, K., \& Chun, S. (2015). Evaluation of internally cured concrete pavement using environmental responses and critical stress analysis. International Journal of Concrete Structures and Materials, 9(4), 463-473.

Kim, K. K., Jeon, S. E., Kim, J. K., \& Yang, S. (2003). An experimental study on thermal conductivity of concrete. Cement and Concrete Research, 33, 363-371.

Kuo, C. M. (1998). Effective temperature differential in concrete pavements. Journal of Transportation Engineering, 124(2), 112-116.

Lam, C. S., Poon, C. S., \& Chan, D. (2007). Enhancing the performance of pre-cast concrete blocks by incorporating waste glass-ASR consideration. Cement \& Concrete Composites, 29, 616-625.

Li, H., Harvey, J., Holland, J., \& Kayhanian, M. (2013). The use of reflective and permeable pavement strategies for heat island mitigation and stormwater management. Environmental Research Letters, 8, 015023.

Li, H., Harvey, J., \& Kendall, A. (2012). Field measurement of albedo for different land cover materials and effects on thermal performance. Journal of Building and Environment, 59, 536-546. doi:10.1016/j.buildenv.2012.10.014.

Michal, R., Witold, M. L., Ewa, K. R., Hubert, D., \& Patrycja, W. (2015). The use of lightweight aggregate saturated with PCM as a temperature stabilizing material for road surfaces. Applied Thermal Engineering, 81, 313-324.

Mindess, S., Young, J. F., \& Darwin, D. (2003). Concrete (2nd ed.). Englewood Cliffs, NJ: Prentice-Hall Inc.

New York State Energy Research and Development Authority. (1997). Use of recycled glass for concrete masonry blocks. Final Report 97-15.

Richardson, M., \& Armaghani, J. M. (1990). Stress caused by temperature gradient in portland cement concrete pavements. Transportation Research Record, 1121, 7-13.

Rohsenow, W. M., Hartnett, J. P., \& Cho, Y. I. (1998). Handbook of heat transfer (3rd ed.). New York, NY: McGrawHill Inc.

Shoukry, S. N, \& Fahmy, M. R. (2002). Optimization of concrete slab geometry for enhanced rigid pavement performance and service life. Department of Mechanical and Aerospace Engineering, College of Engineering and Mineral Resources, West Virginia University, WVDOT Research Project, No. 140.

VENCON 2.0- Software package for structural design of concrete pavements (in Dutch) CROW, Ede, 2004. 